\title{
Manual hyperinflation partly prevents reductions of functional residual capacity in cardiac surgical patients - a randomized controlled trial
}

Frederique Paulus ${ }^{1 *}$, Denise P Veelo ${ }^{1,2}$, Selma B de Nijs ${ }^{3}$, Ludo FM Beenen ${ }^{4}$, Paul Bresser ${ }^{3,5}$, Bas AJM de Mol ${ }^{6}$, Jan M Binnekade ${ }^{1}$ and Marcus J Schultz ${ }^{1}$

\begin{abstract}
Introduction: Cardiac surgery is associated with post-operative reductions of functional residual capacity (FRC). Manual hyperinflation $(\mathrm{MH})$ aims to prevent airway plugging, and as such could prevent the reduction of FRC after surgery. The main purpose of this study was to determine the effect of $\mathrm{MH}$ on post-operative FRC of cardiac surgical patients.

Methods: This was a randomized controlled trial of patients after elective coronary artery bypass graft and/or valve surgery admitted to the intensive care unit (ICU) of a university hospital. Patients were randomly assigned to a "routine MH group" (MH was performed within 30 minutes after admission to the ICU and every 6 hours thereafter, and before tracheal extubation), or a "control group" (MH was performed only if perceptible (audible) sputum was present in the larger airways causing problems with mechanical ventilation, or if oxygen saturation $\left(\mathrm{SpO}_{2}\right)$ dropped below 92\%). The primary endpoint was the reduction of FRC from the day before cardiac surgery to one, three, and five days after tracheal extubation. Secondary endpoints were $\mathrm{SpO}_{2}$ (at similar time points) and chest radiograph abnormalities, including atelectasis (at three days after tracheal extubation).
\end{abstract}

Results: A total of 100 patients were enrolled. Patients in the routine $\mathrm{MH}$ group showed a decrease of FRC on the first post-operative day to $71 \%$ of the pre-operative value, versus $57 \%$ in the control group $(P=0.002)$. Differences in FRC became less prominent over time; differences between the two study groups were no longer statistically significant at Day 5. There were no differences in $\mathrm{SpO}_{2}$ between the study groups. Chest radiographs showed more abnormalities (merely atelectasis) in the control group compared to patients in the routine $\mathrm{MH}$ group $(P=$ 0.002).

Conclusions: $\mathrm{MH}$ partly prevents the reduction of FRC in the first post-operative days after cardiac surgery.

Trial registration: Netherlands Trial Register (NTR): NTR1384. http://www.trialregister.nl

\section{Introduction}

Pulmonary dysfunction is a ubiquitous consequence of cardiac surgery [1]. Alterations in mechanical properties of the lung lead to reductions in pulmonary compliance [2] as well as vital and functional residual capacity (FRC) $[3,4]$ in the first days after surgery. In addition, these patients remain sedated and are nursed in a supine position for several hours, while they are re-

\footnotetext{
*Correspondence: f.paulus@amc.uva.nl

'Department of Intensive Care Medicine, Academic Medical Center,

Meibergdreef 9, $1105 \mathrm{AZ}$, Amsterdam, The Netherlands

Full list of author information is available at the end of the article
}

warmed and weaned from mechanically ventilation. This may reduce mucociliary transport, and as such retention of sputum $[5,6]$

In our setting, a frequently performed intervention as part of airway management of intubated and mechanically ventilated patients is manual hyperinflation $(\mathrm{MH})$ [7-9]. MH aims at mobilization of retained airway secretions in intubated and mechanically ventilated patients, thereby preventing atelectasis $[10,11]$. With $\mathrm{MH}$ the patient is disconnected from the mechanical ventilator, after which the lungs are inflated via a resuscitation bag. The technique consists of several 
factors, including the application of a larger than normal breath (to $150 \%$ of the tidal volume delivered by the mechanical ventilator), the use of a slow inspiratory flow rate (achieved by a slow compression of the resuscitation bag), an inspiratory pause (allowing complete distribution of the inflated air among all the ventilated lung parts) and a high peak expiratory flow achieved by the rapid release of the resuscitation bag. It is imaginable that a higher expiratory than inspiratory flow promotes the outwardly directed motion of airway secretions $[12,13]$.

Although mobilization of airway secretions and prevention of sputum plugging $[11,14]$, and improved alveolar recruitment [10] are cited as potential benefits of bagging, the evidence supporting its efficacy is lacking.

We hypothesized $\mathrm{MH}$ to benefit cardiac surgery patients. Specifically, we hypothesized $\mathrm{MH}$ maneuvers to attenuate the reduction of FRC, to prevent hypoxemia and to prevent atelectasis after cardiac surgery. To test this hypothesis we designed a randomized controlled trial to compare a strategy using frequent $\mathrm{MH}$ maneuvers with a strategy only using $\mathrm{MH}$ if clinically indicated.

\section{Materials and methods}

\section{Patients and setting}

This trial was conducted from February 2009 to March 2010 at the 28-bed intensive care unit (ICU) of the Academic Medical Center, Amsterdam, The Netherlands. The Institutional Review Board approved the study. Preoperative informed consent was obtained from patients scheduled for elective coronary artery bypass graft and/ or valve surgery. Figure 1 presents a timeline depicting the trial interventions.
Pre-operative spirometry was performed within two weeks before surgery by trained respiratory technicians according to the latest recommendations [15]. Patients after previous lung surgery or moderate to severe chronic obstructive pulmonary disease (post-bronchodilator forced expired volume in one second $\left(\mathrm{FEV}_{1}\right)<80 \%$ predicted and the ratio of forced expiratory volume in one second and forced capacity $\left(\mathrm{FEV}_{1} / \mathrm{FVC}\right.$ ratio $\left.)<0.7\right)$ [16] were excluded from participation.

Patients who required repeated cardiac surgery within 48 hours after the index surgical procedure and patients who required prolonged post-operative mechanical ventilation ( $>36$ hours) were excluded from the analysis, since it would be impossible to measure FRC in these patients on the predefined time points.

Preoperative risk factors were scored with the European System for Cardiac Operative Risk Evaluation score (the Euroscore), a scoring system used to predict mortality among cardiac surgery patients [17].

\section{Manual hyperinflation}

Attending ICU nurses performed $\mathrm{MH}$ maneuvers using a standard technique $[18,19]$. Preceding this randomized controlled trial, all ICU nurses took part in an educational program that highlighted the several factors considered important in performing $\mathrm{MH}$ [20]. $\mathrm{MH}$ was performed in the supine position within 30 minutes after connection to the ICU ventilator, repeated every 6 hours and directly before tracheal extubation.

A Mapelson-C circuit with a two liter re-breathing bag (Medicare, Uitgeest, The Netherlands) with the gas flow entry and the expiratory valve located at the patient end of the circuit (a standard bedside resuscitation and manual hyperinflation circuit) was used to perform the maneuver. The circuit was connected to wall oxygen at 15

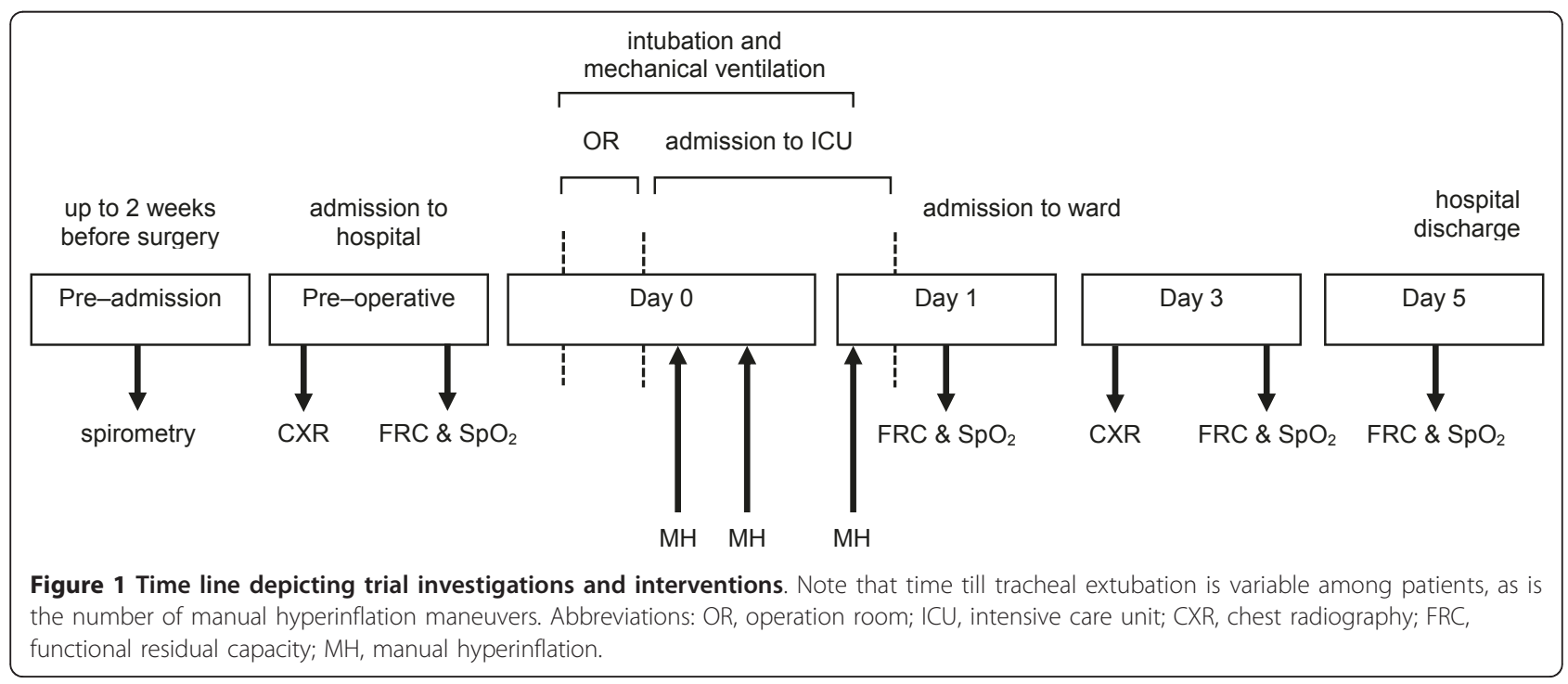


$\mathrm{L} /$ minute and fraction of inspired oxygen $\left(\mathrm{FiO}_{2}\right)$ 1.0. Endotracheal suctioning was performed in sequence with the $\mathrm{MH}$-procedure to remove secretions if mobilized by $\mathrm{MH}$.

\section{Randomization}

On admission to the ICU, patients were randomly assigned to a strategy using frequent $\mathrm{MH}$ maneuvers (the "routine $\mathrm{MH}$ group") or a strategy using $\mathrm{MH}$ only on clinical indication (the "control group"). Randomization was by cards in opaque sealed envelopes drawn by an independent person.

The "routine MH group": A MH maneuver was performed within 30 minutes after connection to the ICUventilator, repeated every 6 hours and directly before tracheal extubation. In case of perceptible sputum $[21,22]$ which could not be removed from the larger airways with endotracheal suctioning, or in case of a drop in oxygen saturation $\left(\mathrm{SpO}_{2},<95 \%\right)$, an additional $\mathrm{MH}$ maneuver could be performed. It was left to the discretion of the attending ICU nurse whether $\mathrm{MH}$ was accompanied by tracheal suction.

The "control group": A MH maneuver was only performed in case of perceptible sputum which could not be removed from the larger airways with endotracheal suctioning, or in case of a drop in $\mathrm{SpO}_{2}(<95 \%)$.

\section{Standard procedures}

Independent anesthesiologists, ICU physicians and nurses not involved in the study carried out standard procedures.

Patients were anesthetized according to the institutional protocol for cardiac surgery; pre-medication consisted of 1 to $2 \mathrm{mg}$ lorazepam and anesthesia was induced by etomidate, sufentanil, and rocuronium. During the surgical procedure, sufentanil (150 to 250 micrograms) was used as an analgesic, and sevoflurane plus propofol were used to maintain anesthesia. Morphine (5 $\mathrm{mg})$ and midazolam $(5 \mathrm{mg})$ were given at the end of the procedure. The ventilatory protocol consisted of volume-controlled ventilation with a tidal volume of 6 to $8 \mathrm{ml} / \mathrm{kg}$, at an inspired oxygen fraction of 0.40 , positive end expiratory pressure of $5 \mathrm{cmH} 20$, inspiratory-toexpiratory ratio of $1: 2$, and a respiratory rate adjusted to achieve normocapnia. Cardiopulmonary bypass was performed under moderate hypothermia $\left(32^{\circ} \mathrm{C}\right)$, using a membrane oxygenator and non-pulsatile blood flow. At the end of anesthesia, all patients were transferred to the ICU with tracheal intubation.

The post-operative ICU protocol involved fluid resuscitation with normal saline and starch solutions, blood transfusion to maintain hemoglobin concentration $\geq 5.0$ $\mathrm{mmol} / \mathrm{L}$, dopamine and norepinephrine in continuous infusion to achieve mean arterial blood pressure $\geq 70$
$\mathrm{mmHg}$, and dobutamine and/or enoximone to achieve a cardiac index $\geq 2.5 \mathrm{~L} /$ minute $/ \mathrm{m}^{2}$ or a mixed venous oxygenation $\geq 60 \%$.

Sedation and analgesics were titrated according to the ICU protocol for cardiac surgery patients. Neuromuscular blocking drugs were never used in the ICU. Propofol was given for sedation via continuous infusion until the core temperature was $\geq 36.0^{\circ} \mathrm{C}$. Acetaminophen $(4 \mathrm{~g} /$ day) was started in all patients. Attending ICU nurses assessed requirement for analgesia during the entire ICU stay. Morphine was given in boluses of 1 to $2 \mathrm{mg}$, and repeated as needed.

The trachea was extubated after achieving general tracheal extubation criteria (that is, responsive and cooperative, hemodynamic stability, chest tube drainage < $100 \mathrm{~mL}$ last hour, having a rectal temperature $>36.0^{\circ} \mathrm{C}$, a respiratory frequency of 10 to 20 breaths/minute without machine-controlled breaths, $\mathrm{FiO}_{2}$ of $40 \%$, and a pressure support level of 5 to $10 \mathrm{cmH}_{2} \mathrm{O}$ for $30 \mathrm{~min}$ utes). After extubation oxygen was administered to the nostrils, typically 3 to $5 \mathrm{~L} /$ minute. If $\mathrm{PaO}_{2}$ was $>100$ $\mathrm{mmHg}(13.3 \mathrm{kPa})$, administration of oxygen was stepwise reduced to $1 \mathrm{~L} /$ minute.

All patients were mobilized early, and had daily routine chest physiotherapy. On the first or second postoperative day, patients were discharged from the ICU and transferred to an intermediate care unit.

\section{Primary endpoint}

The primary endpoint was the change of FRC from the day before cardiac surgery to one, three, and five days after tracheal extubation. FRC measurements were performed with use of the "He re-breathing technique" (Masterscreen-PFT; Jaeger, Wurzberg, Germany) according to the European Respiratory Society recommendations [23]. During FRC measurements, patients were breathing room air while in bed in the upright sitting position. The mean value of 2 technical acceptable measurements was recorded. All measurements were performed by the same investigator recorded who was blinded for randomization groups.

\section{Secondary endpoints}

Pulse-oximeter oxygen saturation $\left(\mathrm{SpO}_{2}\right)$ was measured with commercial pulse- oximeters (IntelliVue pulse-oxymetrie; Philips, Eindhoven, The Netherlands; or Datascope 'Duo' with Masimo SET ${ }^{\circledR}$, Hoevelaken, The Netherlands) during the first five days after tracheal extubation. $\mathrm{SpO}_{2}$ was measured for 10 minutes while the patient was breathing room air. Measurements were terminated when $\mathrm{SpO}_{2}$ dropped to a level $\leq 90 \%$. The latter was defined as hypoxemia, and supplemental oxygen therapy was continued with its occurrence. 
Chest radiographs were obtained in a sitting position, both pre-operative and on the third post-operative day. An independent radiologist blinded for randomization groups interpreted the chest radiographs. Each radiograph was evaluated for the presence of atelectasis, pulmonary infiltrate, extra-vascular lung fluid, pleural fluid, and pneumothorax. The presence of atelectasis was graded as: no atelectasis ("0"); plate or sub-segmental atelectasis ("1"); segmental atelectasis ("2"); or lobair atelectasis ("3"); for the purpose of this study, extent of other abnormalities was graded as: not present ("0"); mild ("1"); moderate ("2"); or severe ("3").

\section{Other data collected}

These included the number of $\mathrm{MH}$ maneuvers per patient; demographics (age, gender, body weight, body height, type of surgery), duration of anesthesia, anesthetics given to the patient during surgery, duration until tracheal extubation and length of stay in ICU and hospital, propofol and morphine dose in the ICU.

\section{Power calculation}

This trial was designed to detect a $300 \mathrm{~mL}$ difference in the post-operative FRC between the two study groups (10). A sample size of 42 in each group would have $80 \%$ power to detect a difference in means of $-300 \mathrm{~mL}$ (the difference between a Group 1 mean, of $1.900 \mathrm{~mL}$ and a Group 2 mean, of $2.200 \mathrm{~mL}$ ), assuming that the FRC standard deviation was $480 \mathrm{~mL}$ using analysis of variance (ANOVA) for repeated measurements with a 0.05 two-sided significance level. Based on an anticipated drop-out of 15 to $20 \%$ we randomized a total of 100 patients.

\section{Statistical analysis}

Data were presented as mean with standard deviation (SD) or medians with interquartile range (IQR) where appropriate. Descriptive statistics were used to summarize patient characteristics. Differences in FRC and $\mathrm{SpO}_{2}$ at the different time points were compared by analysis of variance (ANOVA) for repeated measurements. Categorical variables (hypoxic periods, chest radiograph data and $\mathrm{MH}$ data) were compared between groups by $\mathrm{X}^{2}$ tests. All participants were analyzed in the groups that they were allocated to. The level of significance was set at 0.05. All analyses were performed using SPSS for Windows (version 18.0, SPSS Inc., Chicago, IL, USA).

\section{Results}

One hundred patients were randomly assigned to one of the two groups (Figure 2). Seven patients (four in the routine $\mathrm{MH}$ group and three in the control group) were not analyzed because they needed repeated cardiac surgery. In nine patients (six in the routine $\mathrm{MH}$ group and three in the control group) FRC measurements could not be performed on predefined time points because of tracheal extubation $>48$ hours or re-intubation for cardiac instability (10). In three other patients, (one in the routine $\mathrm{MH}$ group and two in the control group), FRC measurements could not be performed on predefined time points because of tracheal extubation $>48$ hours because of respiratory failure (2).

Two patients died; one patient in the routine $\mathrm{MH}$ group died of bowel ischemia after four days; one patient in the control group died due to cardiac failure.

Groups were comparable for all demographic data (Table 1). No differences were found for time till tracheal extubation or stay in ICU or hospital. Administered analgesics, sedatives and blood products were similar between groups. Ventilator data are given in Table 2

\section{MH maneuvers}

Patients in the routine $\mathrm{MH}$ group received median (IQR) 2 (2 to 3) MH maneuvers compared to 0 (0 to 0 ) in the control group $(P<0.001)$. Endotracheal suction was performed 2.5 ( 2 to 4 ) times in the patients in the routine $\mathrm{MH}$ group compared to 1 (1 to 2 ) in the patients in the control group $(P<0.001)$.

\section{Changes in FRC}

In both groups, FRC was significantly reduced after cardiac surgery (from $2.840 \mathrm{ml} \pm 720$ to $1,815 \mathrm{ml} \pm 540$ $\mathrm{ml}$, difference $=1.025 \mathrm{ml}, 95 \% \mathrm{CI} 877$ to $1,176 \mathrm{ml}, P<$ 0.001) (Figure 3).

In the routine $\mathrm{MH}$ group FRC decreased on the first post operative day to $71 \%$ of the pre-operative value (from $2.875 \pm 565 \mathrm{~mL}$ to $2.055 \pm 540 \mathrm{~mL}$ ), while in the control group FRC decreased to $57 \%$ of pre-operative level (from $2.808 \pm 650 \mathrm{~mL}$ to $1.588 \pm 530 \mathrm{~mL}$ ). The difference was $400 \mathrm{~mL}, 95 \%$ CI 680 to $115 \mathrm{~mL}, P=$ 0.002).

The absolute reduction in FRC at Day 3 was lower in the routine $\mathrm{MH}$ strategy group $(750 \pm 565 \mathrm{~mL})$ compared to the control group $(1,056 \pm 570 \mathrm{~mL})$ (difference $=306 \mathrm{~mL}, 95 \%$ CI 593 to $20 \mathrm{~mL} P=0.04)$. Differences in decreases of FRC between the two study groups were no longer statistical significant at Day $5(760 \pm 500 \mathrm{~mL}$ in the routine $\mathrm{MH}$ group and $730 \pm 530 \mathrm{~mL}$ and the control group, respectively).

\section{Oxygenation}

There were no differences between groups in $\mathrm{PaO}_{2} /$ $\mathrm{FiO}_{2}$, either within one hour after admission to the ICU or during intubation and mechanical ventilation. Hypoxemia on the first post-operative day occurred in $17 \%$ of the patients in the $\mathrm{MH}$ group versus $28 \%$ of the patients in the control group, at Day 3 in 13\% in the $\mathrm{MH}$ group 


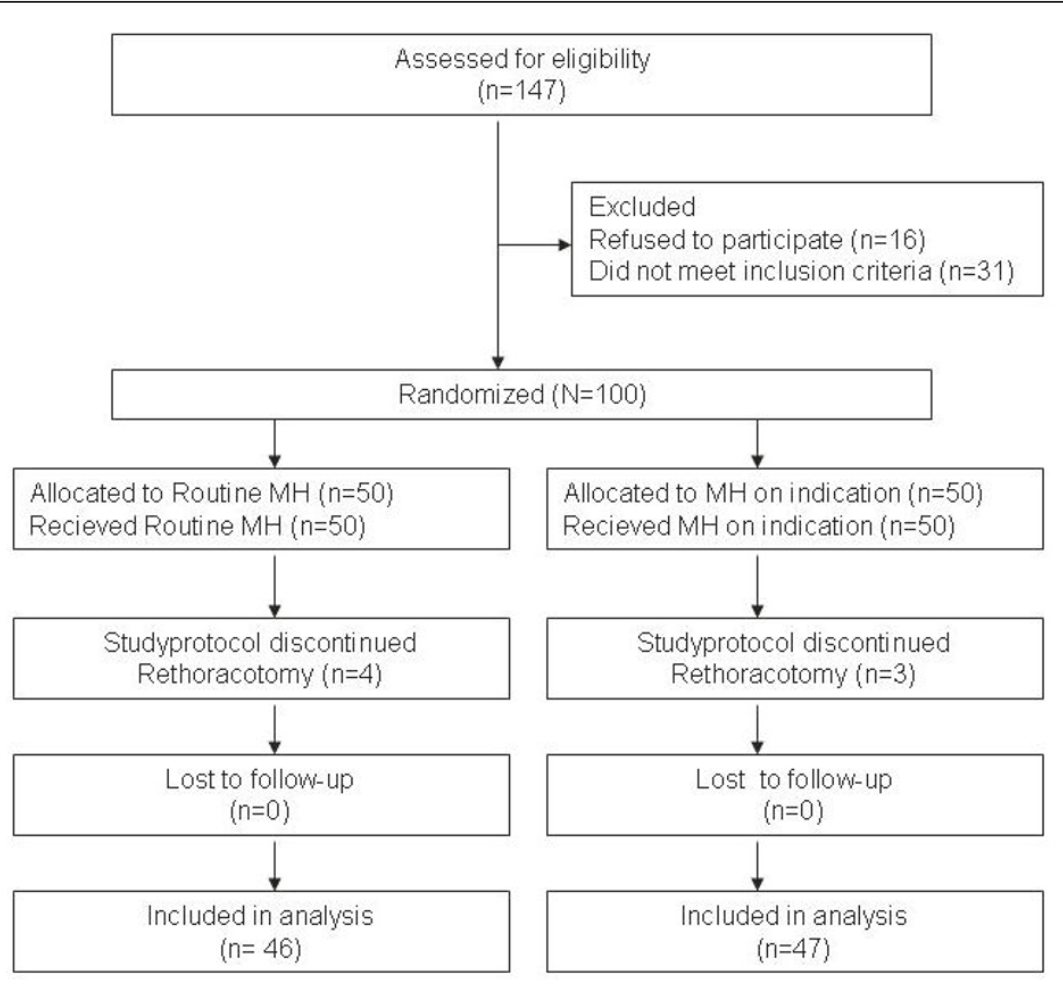

Figure 2 CONSORT diagram of the trial.

versus $21 \%$ in the control group. At Day 5, hypoxemia occurred in $8 \%$ of the patients in both groups. Differences did not reach statistical significance (Table 3).

\section{Chest radiographs}

Pre-operative chest radiographs showed no atelectasis. At Day 3 more patients in the control group had atelectasis compared to patients in the routine $\mathrm{MH}$ strategy group (Table 4). However, there was no difference in the atelectasis score between the two groups. Pneumothorax was found in two patients, one in each study group. A mild pulmonary infiltrate was found in one patient in the routine $\mathrm{MH}$ group; moderate pulmonary infiltrates were found in two patients, one in each study group.

\section{Discussion}

The results of our randomized controlled trial can be summarized as follows: (1) FRC is significantly reduced in patients after cardiac surgery for several days; (2) MH partly prevents this reduction; (3) the incidence of signs of atelectasis on chest radiographs differed between groups.

Our study is the first randomized controlled trial assessing the effects of $\mathrm{MH}$ on FRC in patients after cardiac surgery. Its findings are in line with the results of other studies suggesting that $\mathrm{MH}$ may benefit patients after surgery. A previous randomized controlled trial showed early $\mathrm{MH}$ to improve $\mathrm{PaO}_{2}$ and static compliance in patients after myocardial re-vascularisation [24]. Also, $\mathrm{MH}$ reduced duration of mechanical ventilation in that trial. Another randomized controlled trial confirmed $\mathrm{MH}$ to improve oxygenation after surgery [25].

The reduction of FRC and the presence of atelectasis after cardiac surgery in our trial are consistent with findings in previously published studies of cardiac surgery patients. In one study deterioration of pulmonary function was frequently seen after cardiac surgery, with FRC reductions of 40 to $50 \%$ during the first 24 hours after tracheal extubation [26]. Also, incidence of signs of atelectasis on chest radiographs occurred in up to $90 \%$ of patients after cardiac surgery, and its presence was associated with a larger decrement in pulmonary function. In another study, atelectasis persisted for several days after surgery, was likely to be a focus of infection and could have been a contributing factor to pulmonary complications [27].

Plugging of airway secretions may lead to airway obstructions, thereby causing gas resorption distal to the obstructions in patients who are mechanically ventilated. Beneficial effects of $\mathrm{MH}$ on clearance of airway secretion have been demonstrated before [14]. Higher expiratory than inspiratory flows generated with $\mathrm{MH}$ is the proposed mechanisms that contribute to clearance of 
Table 1 Characteristics of the study population

\begin{tabular}{|c|c|c|}
\hline & $\begin{array}{l}\text { Routine MH } \\
(\mathrm{N}=50)\end{array}$ & $\begin{array}{l}\text { Control } \\
(\mathrm{N}=50)\end{array}$ \\
\hline \multicolumn{3}{|l|}{ Demographics } \\
\hline Age, yrs & $65 \pm 10.2$ & $60.3 \pm 13.5$ \\
\hline Male, $\mathrm{n}$ & 35 & 38 \\
\hline $\mathrm{BMI}, \mathrm{kg} / \mathrm{m}^{2}$ & $25.8 \pm 4.2$ & $26.7 \pm 4.7$ \\
\hline FEV1, \% & $95 \pm 14$ & $99 \pm 16$ \\
\hline FVC, \% & $101 \pm 14$ & $101 \pm 15$ \\
\hline EuroScore, \% & $5.4 \pm 2.7$ & $4.4 \pm 2.8$ \\
\hline Current smokers, $\mathrm{n}$ & 14 & 10 \\
\hline \multicolumn{3}{|l|}{ Type of surgery } \\
\hline$C A B G, n$ & 13 & 16 \\
\hline Valve surgery, $\mathrm{n}$ & 29 & 24 \\
\hline Combined CABG/valve surgery, $\mathrm{n}$ & 8 & 10 \\
\hline LIMA, n & 20 & 22 \\
\hline \multicolumn{3}{|l|}{ Intra-operative and intensive care characteristics } \\
\hline Duration of surgery, minutes & $305 \pm 84$ & $300 \pm 73$ \\
\hline CPB time, minutes & $134 \pm 58$ & $128 \pm 61$ \\
\hline Total sufentanil dose, microgram & 188 (143 to 250$)$ & 250 (150 to 250$)$ \\
\hline Total midazolam dose, mg & 15 (9 to 20$)$ & 15 (5 to 25$)$ \\
\hline Total morphine dose, mg & 21 (9 to 20$)$ & 15 (5 to 25$)$ \\
\hline Total propofol dose, mg & 1.250 (785 to 1.800$)$ & 1.478 (1.060 to 2.010$)$ \\
\hline WBC on ICU admission $\left(\times 10^{6}\right)$ & $10 \pm 3$ & $10 \pm 3$ \\
\hline Core temperature on ICU admission $\left({ }^{\circ} \mathrm{C}\right)$ & $35.7 \pm 0.8$ & $35.6 \pm 0.9$ \\
\hline Sedation duration (ICU), hours & $3.9(2.0$ to 13.9$)$ & 3.5 (2.3 to 18.0$)$ \\
\hline Duration of tracheal intubation (ICU), hours & 10.5 (6.5 to 16.0$)$ & 10.8 (7.3 to 24.6$)$ \\
\hline Length of stay (ICU), hours & 23.2 (20.8 to 44.8$)$ & 23.2 (20.7 to 46.3 ) \\
\hline Length of stay (hospital), days & 5.3 (4.3 to 7.4$)$ & 5.4 (4.4 to 7.2$)$ \\
\hline
\end{tabular}

Data are presented as mean $\pm \mathrm{SD}$ or median (IQR).

Abbreviations: BMI, body mass index; CABG, coronary artery bypass graft; FEV1, forced expired volume in one second, expressed as percentage of predicted value; FVC, vital capacity, expressed as percentage of predicted value; EuroScore, based on system predicting mortality with cardiac surgery (\%); CPB, cardio pulmonary bypass; LIMA, left internal mammary artery; WBC, white blood cell count.

airway secretions in intubated and mechanically ventilated patients. In accordance, in our study endotracheal suction was performed more often in patients in the

\section{Table 2 Respiratory data}

\begin{tabular}{|c|c|c|c|c|}
\hline & & $\begin{array}{l}\text { Routine } M H \\
\quad(\mathrm{~N}=46)\end{array}$ & $\begin{array}{l}\text { Control } \\
(\mathrm{N}=47)\end{array}$ & $P$-value \\
\hline \multirow[t]{2}{*}{ PEEP $(\mathrm{cmH} 2 \mathrm{O})$} & OR & $5 \pm 0.1$ & $5 \pm 0.1$ & $P=0.90$ \\
\hline & $\mathrm{ICU}$ & $5 \pm 1$ & $6 \pm 2$ & $P=0.20$ \\
\hline \multirow[t]{2}{*}{$\mathrm{PIP}\left(\mathrm{cmH}_{2} \mathrm{O}\right)$} & OR & $16 \pm 3$ & $16 \pm 3$ & $P=0.70$ \\
\hline & $\mathrm{ICU}$ & $17 \pm 3$ & $18 \pm 3$ & $P=0.15$ \\
\hline \multirow[t]{2}{*}{ Tidal volume (ml/kg IBW) } & OR & $7.7 \pm .1 .2$ & $7.4 \pm 1.2$ & $P=0.20$ \\
\hline & $\mathrm{ICU}$ & $7.9 \pm 1.3$ & $7.9 \pm 1.3$ & $P=0.82$ \\
\hline \multirow[t]{2}{*}{ Maximum $\mathrm{FiO}_{2}$} & OR & $0.85 \pm 0.17$ & $0.82 \pm 0.19$ & $P=0.43$ \\
\hline & ICU & $0.53 \pm 0.9$ & $0.50 \pm 0.17$ & $P=0.28$ \\
\hline \multirow[t]{2}{*}{$\mathrm{FiO}_{2}$} & OR & $0.48 \pm 0.12$ & $0.48 \pm 0.12$ & $P=0.87$ \\
\hline & $\mathrm{ICU}$ & $0.47 \pm 0.09$ & $0.47 \pm 0.07$ & $P=0.97$ \\
\hline
\end{tabular}

Data are presented as mean \pm SD.

Abbreviations: PEEP, Positive End Expiratory Pressure; OR, Operating Room; ICU, Intensive Care Unit; PIP, Positive Inspiratory Pressure; IBW, Ideal Body weight; $\mathrm{FiO}_{2}$, Fraction of inspired oxygen. routine group compared to patients who received on demand $\mathrm{MH}$, suggesting improved clearance of secretions necessitating airway suctioning. Unfortunately, the amount and appearance of eliminated secretions were not compared between groups, which could be seen as a limitation of our trial.

Our data suggest that MH could contribute to the recovery of collapsed lung areas after cardiac surgery. Delivering increased tidal volumes with an inspiratory pause via $\mathrm{MH}$ could generate transpulmonary pressures that could overcome, at least in part, alveolar collapses [28]. Earlier studies concluded that for complete reopening of collapsed lung tissue inspirations are required that reach airway pressures of $40 \mathrm{cmH}_{2} \mathrm{O}$ which are maintained for eight to nine seconds [29]. Certainly, $\mathrm{MH}$ is not capable of providing such pressures for longer than a few seconds. However, shortlasting natural occurring maneuvers, such as coughing and sighs, also result in recruiting of lung tissue.

Hypoxemia occurred in 23\% of patients at Day 1 after tracheal extubation. These findings were in contrast to 


\section{FRC (L)}

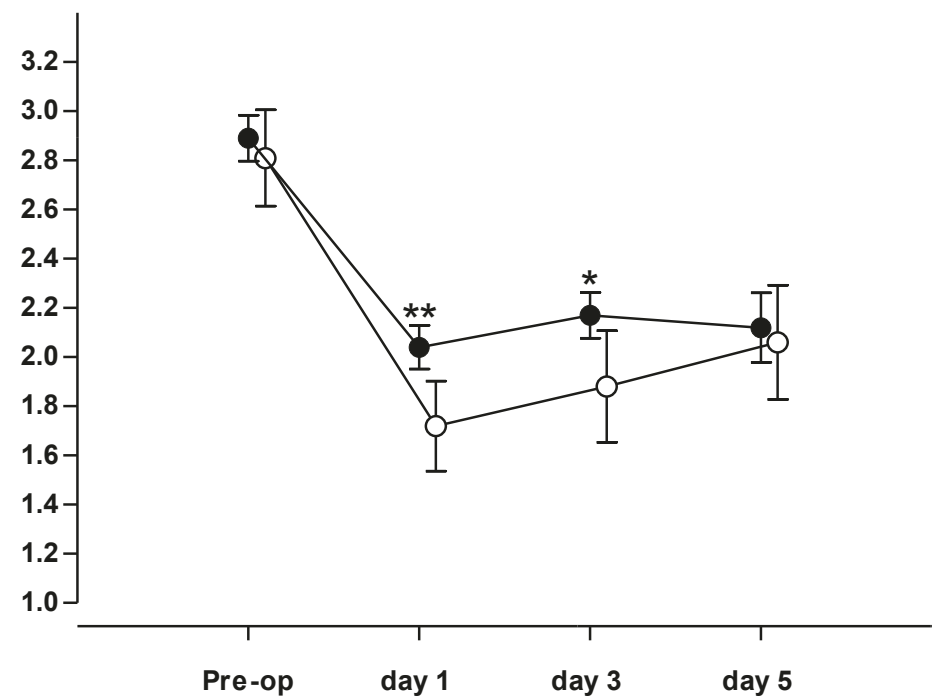

Figure 3 Measurements of functional residual capacity. Preoperative functional residual capacity (FRC (L) mean 95\% Cl) and FRC at one, three and five days after tracheal extubation in routine $\mathrm{MH}\left(\mathrm{N}=37\right.$; closed symbols) and control group $\left(\mathrm{N}=41\right.$; open symbols). ${ }^{*}, P<0.04,{ }^{* *}, P$ $<0.002$.

previous studies, which report up to $60 \%$ of patients with hypoxic periods within the first two days after tracheal extubation $[26,30]$. There are several possible explanations as to why $\mathrm{MH}$ in our trial did not result in a greater difference in the presence of hypoxemia. One reason could be that oxygenation not only results from changes in (regional) ventilation but also from changes in (regional) perfusion. Hypoxic pulmonary vasoconstriction may be responsible for maintaining the ventilation-perfusion ratio during localized alveolar hypoxia. Thus, if hypoxic pulmonary vasoconstriction works, oxygenation is preserved even during atelectasis. This could, at least in part, explain our findings. Another reason could have been the use of the pulse-oximeter to detect hypoxemia. Although the pulse-oximeter is an device with a reasonable degree of accuracy, the performance of the pulse-oximeter can be disrupted by several, including poor peripheral perfusion and peripheral vasoconstriction [31]. We cannot exclude the possibility that the pulse-oximeter was not discriminative enough. It may be more plausible that our trial was insufficiently powered to detect a difference in hypoxemia between groups.

The incidence of signs of atelectasis on chest radiographs differed between groups. Indeed, significantly fewer patients in the routine $\mathrm{MH}$ group had radiographic signs of atelectasis. Reasons for atelectasis after cardiac surgery are multiple and include higher levels of intra-operative $\mathrm{FiO}_{2}$, type of surgery, obesity and postoperative pain. Absorption atelectasis during mechanical

Table 3 Clinical outcome data

\begin{tabular}{|c|c|c|c|}
\hline & $\begin{array}{l}\text { routine MH group } \\
(\mathrm{N}=46)\end{array}$ & $\begin{array}{c}\text { control group } \\
(\mathrm{N}=47)\end{array}$ & $P$-value \\
\hline First $\mathrm{PaO}_{2} / \mathrm{FiO}_{2}$ (one hour after admission) $(\mathrm{mmHg}$ ) & $339 \pm 127$ & $329 \pm 126$ & $P=0.70$ \\
\hline Worst $\mathrm{PaO}_{2} / \mathrm{FiO}_{2}$, (while intubated and mechanically ventilated) $(\mathrm{mmHg})$ & $213 \pm 70$ & $221 \pm 82$ & $P=0.60$ \\
\hline Hypoxemia - Day 1 (n (\%)) & $8(17)$ & $13(28)$ & $P=0.23$ \\
\hline Hypoxemia - Day 3 (n (\%)) & $6(13)$ & $10(21)$ & $P=0.29$ \\
\hline Hypoxemia - Day 5 (n (\%)) & $3(8)$ & $3(8)$ & $P=0.60$ \\
\hline $\mathrm{SpO}_{2}$ - Day $1(\%)$ & 95 (93 to 97$)$ & 94 (90 to 97$)$ & $P=0.75$ \\
\hline $\mathrm{SpO}_{2}-$ Day $3(\%)$ & 95 (91 to 96$)$ & 94 (92 to 96$)$ & $P=0.75$ \\
\hline $\mathrm{SpO}_{2}$ - Day $5(\%)$ & 96 (94 to 97$)$ & 96 (95 to 97 ) & $P=0.75$ \\
\hline
\end{tabular}

Data are presented as percentages of $\mathrm{N}(\%)$, medians (IQR) or means $\pm \mathrm{SD}$. Hypoxemia was defined as a drop of $\mathrm{SpO} 2 \leq 90 \%$ within five minutes after cessation of oxygen supply.

Abbreviations: $\mathrm{SpO}_{2}$, peripheral oxygen saturation; $\mathrm{PaO}_{2}$, partial pressure of arterial oxygen; $\mathrm{FiO}_{2}$, fraction of inspired oxygen. 
Table 4 Chest radiograph results

\begin{tabular}{lccc}
\hline & $\begin{array}{c}\text { routine } \mathbf{M H} \text { group } \\
(\mathbf{N}=\mathbf{4 6})\end{array}$ & $\begin{array}{c}\text { control group } \\
(\mathbf{N}=\mathbf{4 7})\end{array}$ & $P$-value \\
\hline No atelectasis & $8(17)$ & $0(0)$ & $P=0.002$ \\
Plate/subsegmental atelectasis & $20(44)$ & $22(47)$ & $P=0.10$ \\
Segmental atelectasis (one of two segments) & $18(39)$ & $23(49)$ & $P=0.55$ \\
Lobar atelectasis & $0(0)$ & $2(4)$ & $P=0.16$ \\
\hline
\end{tabular}

Data are presented as percentages of $\mathrm{N}(\%)$

ventilation is most likely to occur when levels of $\mathrm{FiO}_{2}$ are high [27]. Indeed, higher levels of $\mathrm{FiO}_{2}$ during mechanical ventilation because of general anesthesia during surgery are associated with atelectasis formation $[27,32]$. Another causative factor could be the harvesting of the internal mammary artery [33]. Use of the internal mammary artery graft has been found to be associated with a greater occurrence of post-operative atelectasis. Finally, post-operative pain leads to impairment of deep breaths and, therefore, could enhance formation of atelectasis [34]. The differences between groups could not be explained by the above-mentioned factors, since they affected both groups to the same extent.

$\mathrm{MH}$ may cause a short-term state of hyperinflation and as such it can be questioned if $\mathrm{MH}$ is a safe procedure. We, and others, have studied possible adverse effects of MH $[19,35,36]$. These studies suggested that $\mathrm{MH}$, when performed under controlled conditions and/ or performed by experienced and trained nurses, has negligible side-effects. In our previous experiences we neither registered side-effects prospectively nor did we evaluate patient comfort in the present trial.

We excluded patients who required prolonged postoperative mechanical ventilation ( $>36$ hours) from analysis of the primary endpoint, since it was impossible to measure FRC in these patients on the predefined time points. We explicitly intended to study post-extubation changes in FRC, since FRC is affected by intubation and mechanically ventilation, especially when positive end expiratory pressure (PEEP) is applied (as was the case for all these patients). The patients, who were excluded from the analysis of the primary endpoint, were analyzed for secondary endpoints. The analysis of the secondary endpoints supports the analysis of the primary endpoint.

We recognize several other limitations of our study. First, the bedside FRC measurement is not the most optimal technique for quantifying lung aeration. Frequent computer tomography scanning, considered the gold standard for quantifying lung aeration, however, could not be performed for obvious reasons [37]. Nevertheless, recently bedside FRC measurement techniques have been evaluated with acceptable accuracy and repeatability [38]. In addition, in another study changes in FRC after alveolar de- and re-recruitment could be easily assessed [39]. A second limitation is that we did not measure $\mathrm{MH}$ parameters considered important for its efficacy. However, we recently showed that the implementation of $\mathrm{MH}$ guidelines, guided by individual feedback and educational meetings led to consistent $\mathrm{MH}$ performance [20]. A third limitation considers generalizability of our findings. Our study was a single-center trial, and practice may differ elsewhere. For instance, tracheal intubation times in our cohort are different from those reported elsewhere.

\section{Conclusions}

$\mathrm{MH}$ partly prevents reduction of FRC in patients after cardiac surgery in the first post-operative days. In accordance, the incidence of signs of atelectasis on post-operative chest radiographs is significant lower in patients who receive $\mathrm{MH}$. Future studies are needed to determine the effect of $\mathrm{MH}$ on important clinical endpoints, including duration of tracheal intubation, post-operative pulmonary complications and duration of hospitalization.

\section{Key messages}

- In patients after cardiac surgery, reduction of FRC is partly prevented by manual hyperinflation.

- The incidence of signs of atelectasis on post-operative chest radiographs in patients after cardiac surgery is lower in patients who receive manual hyperinflation.

\section{Abbreviations}

ANOVA: analysis of variance; BMI: body mass index; CABG: coronary artery bypass graft; CXR: chest radiography; CPB: cardio pulmonary bypass; FEV1: forced expired volume in one second, expressed as percentage of predicted value; FEV1/FVC: ratio of forced expiratory volume in one second and forced capacity; $\mathrm{FiO}_{2}$ : fraction of inspired oxygen; FRC: functional residual capacity; FVC: forced vital capacity, expressed as percentage of predicted value; IBW: ideal body weight; ICU: intensive care unit; IQR: interquartile range; LIMA: left internal mammary artery; $\mathrm{MH}$ : manual hyperinflation; OR: operating room; $\mathrm{PaO}_{2}$ : partial pressure of arterial oxygen; $\mathrm{PaO}_{2} / \mathrm{FiO}_{2}$ : ratio of partial pressure of arterial oxygen and fraction of inspired oxygen; PEEP: positive end expiratory pressure; PIP: positive inspiratory pressure; SD: standard deviation; $\mathrm{SpO}_{2}$ : peripheral oxygen saturation; WBC: white blood cell count.

\section{Acknowledgements}

No funding sources were used for this study.

\section{Author details}

${ }^{1}$ Department of Intensive Care Medicine, Academic Medical Center, Meibergdreef 9, 1105 AZ, Amsterdam, The Netherlands. 'Department of Anesthesiology, Academic Medical Center, Meibergdreef 9, 1105 AZ, 
Amsterdam, The Netherlands. ${ }^{3}$ Department of Respiratory Medicine, Academic Medical Center, Meibergdreef 9, 1105 AZ, Amsterdam, The Netherlands. ${ }^{4}$ Department of Radiology, Academic Medical Center, Meibergdreef 9, $1105 \mathrm{AZ}$, Amsterdam, The Netherlands. ${ }^{5}$ Department of Respiratory Medicine, Onze Lieve Vrouwe Gasthuis, Oosterpark 91091 AC, Amsterdam, The Netherlands. ${ }^{6}$ Department of Cardiothoracic Surgery, Academic Medical Center, Meibergdreef 9, 1105 AZ, Amsterdam, The Netherlands.

\section{Authors' contributions}

FP contributed to the conception and design of the trial, data collection, statistical analysis, and writing of the manuscript. DPV contributed to data collection, and the revision of the manuscript. SBdeN contributed to the study design, data collection and the revision of the manuscript. LFB contributed to the data collection, and the revision of the manuscript. PB contributed to the study design and the revision of the manuscript. BAdeM contributed to the study design and the revision of the manuscript. JMB contributed to the conception and design of the trial, statistical analysis and writing of the manuscript. MJS contributed to the conception and design of the trial, interpretation of the data and writing of the manuscript. All authors read and approved the final version of the manuscript.

\section{Competing interests}

The authors declare that they have no competing interests.

Received: 6 April 2011 Revised: 21 June 2011 Accepted: 5 August 2011 Published: 5 August 2011

\section{References}

1. Wynne R, Botti M: Postoperative pulmonary dysfunction in adults after cardiac surgery with cardiopulmonary bypass: clinical significance and implications for practice. Am J Crit Care 2004, 13:384-393.

2. Chaney MA, Nikolov MP, Blakeman B, Bakhos M, Slogoff S: Pulmonary effects of methylprednisolone in patients undergoing coronary artery bypass grafting and early tracheal extubation. Anesth Analg 1998, 87:27-33.

3. Shapira N, Zabatino SM, Ahmed S, Murphy DM, Sullivan D, Lemole GM: Determinants of pulmonary function in patients undergoing coronary bypass operations. Ann Thorac Surg 1990, 50:268-273.

4. Johnson D, Hurst T, Thomson D, Mycyk T, Burbridge B, To T, Mayers I: Respiratory function after cardiac surgery. I Cardiothorac Vasc Anesth 1996, 10:571-577.

5. Dolovich M, Rushbrook J, Churchill E, Mazza M, Powles AC: Effect of continuous lateral rotational therapy on lung mucus transport in mechanically ventilated patients. J Crit Care 1998, 13:119-125.

6. Marik PE, Fink MP: One good turn deserves another! Crit Care Med 2002, 30:2146-2148.

7. Paulus F, Binnekade JM, Middelhoek P, Schuitz MJ, Vroom MB: Manual hyperinflation of intubated and mechanically ventilated patients in Dutch intensive care units-a survey into current practice and knowledge. Intensive Crit Care Nurs 2009, 25:199-207.

8. King D, Morrell A: A survey on manual hyperinflation as a physiotherapy technique in intensive care units. Physiotherapy 1992, 78:747-750.

9. Hodgson C, Carroll S, Denehy L: A survey of manual hyperinflation in Australian hospitals. Aust J Physiother 1999, 45:185-193.

10. Maa SH, Hung TJ, Hsu KH, Hsieh YI, Wang KY, Wang CH, Lin HC: Manual hyperinflation improves alveolar recruitment in difficult-to-wean patients. Chest 2005, 128:2714-2721.

11. Jones AY: Secretion movement during manual lung inflation and mechanical ventilation. Respir Physiol Neurobiol 2002, 132:321-327.

12. Benjamin RG, Chapman GA, Kim CS, Sackner MA: Removal of bronchial secretions by two-phase gas-liquid transport. Chest 1989, 95:658-663.

13. Kim CS, Iglesias AJ, Sackner MA: Mucus clearance by two-phase gas-liquid flow mechanism: asymmetric periodic flow model. J Appl Physiol 1987, 62:959-971.

14. Hodgson C, Denehy L, Ntoumenopoulos G, Santamaria J, Carroll S: An investigation of the early effects of manual lung hyperinflation in critically ill patients. Anaesth Intensive Care 2000, 28:255-261.

15. Miller MR, Hankinson J, Brusasco V, Burgos F, Casaburi R, Coates A, Crapo R, Enright P, van der Grinten CP, Gustafsson P, Jensen R, Johnson DC, Maclntyre N, McKay R, Navajas D, Pedersen OF, Pellegrino R, Viegi G,
Wanger J, ATS/ERS Task Force: Standardisation of spirometry. Eur Respir J 2005, 26:319-338.

16. Rabe KF, Hurd S, Anzueto A, Barnes PJ, Buist SA, Calverley P, Fukuchi Y, Jenkins C, Rodriguez-Roisin R, van Weel C, Zielinski J, Global Initiative for Chronic Obstructive Lung Disease: Global strategy for the diagnosis, management, and prevention of chronic obstructive pulmonary disease: GOLD executive summary. Am J Respir Crit Care Med 2007, 176:532-555.

17. Roques F, Nashef $S A$, Michel P, Gauducheau E, de Vincentiis $C$, Baudet $E$ Cortina J, David M, Faichney A, Gabrielle F, Gams E, Harjula A, Jones MT, Pintor PP, Salamon R, Thulin L: Risk factors and outcome in European cardiac surgery: analysis of the EuroSCORE multinational database of 19030 patients. Eur J Cardiothorac Surg 1999, 15:816-822.

18. Maxwell $L$, Ellis ER: Pattern of ventilation during manual hyperinflation performed by physiotherapists. Anaesthesia 2007, 62:27-33.

19. Paulus F, Binnekade JM, Vermeulen M, Vroom MB, Schultz MJ: Manual hyperinflation is associated with a low rate of adverse events when performed by experienced and trained nurses in stable critically ill patientsa prospective observational study. Minerva Anestesiol 2010, 76:1036-1042.

20. Paulus F, Binnekade JM, Middelhoek P, Vroom MB, Schultz MJ: Feedback and education improve manual hyperinflation maneuvers. Am J Respir Crit Care Med 2009, 179:A2306.

21. AARC Clinical Practice Guidelines. Endotracheal suctioning of mechanically ventilated patients with artificial airways 2010. Respir Care 2010, 55:758-764.

22. Guglielminotti J, Alzieu M, Maury E, Guidet B, Offenstadt G: Bedside detection of retained tracheobronchial secretions in patients receiving mechanical ventilation: is it time for tracheal suctioning? Chest 2000, 118:1095-1099.

23. Wanger J, Clausen JL, Coates A, Pedersen OF, Brusasco V, Burgos F, Casaburi R, Crapo R, Enright P, van der Grinten CP, Gustafsson P, Hankinson J, Jensen R, Johnson D, Macintyre N, McKay R, Miller MR, Navajas D, Pellegrino R, Viegi G: Standardisation of the measurement of lung volumes. Eur Respir J 2005, 26:511-522

24. Blattner C, Guaragna JC, Saadi E: Oxygenation and static compliance is improved immediately after early manual hyperinflation following myocardial revascularisation: a randomised controlled trial. Aust $J$ Physiother 2008, 54:173-178.

25. Patman $\mathrm{S}$, Jenkins $\mathrm{S}$, Stiller K: Manual hyperinflation-effects on respiratory parameters. Physiother Res Int 2000, 5:157-171.

26. Reis Miranda D, Struijs A, Koetsier P, van Thiel R, Schepp R, Hop W, Klein J, Lachmann B, Bogers AJ, Gommers D: Open lung ventilation improves functional residual capacity after extubation in cardiac surgery. Crit Care Med 2005, 33:2253-2258.

27. Hedenstierna $G$, Edmark L: Mechanisms of atelectasis in the perioperative period. Best Pract Res Clin Anaesthesiol 2010, 24:157-169.

28. Anderson JB, Qvist J, Kann T: Recruiting collapsed lung through collateral channels with positive end-expiratory pressure. Scand J Resp Dis 2011, 60:260-266.

29. Rothen HU, Neumann P, Berglund JE, Valtysson J, Magnusson A Hedenstierna G: Dynamics of re-expansion of atelectasis during general anaesthesia. Br J Anaesth 1999, 82:551-556.

30. Taggart DP: Respiratory dysfunction after cardiac surgery: effects of avoiding cardiopulmonary bypass and the use of bilateral internal mammary arteries. Eur J Cardiothorac Surg 2000, 18:31-37.

31. Jubran A: Pulse oximetry. Crit Care 1999, 3:R11-R17.

32. Rothen HU, Sporre B, Engberg G, Wegenius G, Reber A, Hedenstierna G: Prevention of atelectasis during general anaesthesia. Lancet 1995, 345:1387-1391.

33. Wheatcroft M, Shrivastava V, Nyawo B, Rostron A, Dunning J: Does pleurotomy during internal mammary artery harvest increase postoperative pulmonary complications? Interact Cardiovasc Thorac Surg 2005, 4:143-146.

34. Wahba RW: Perioperative functional residual capacity. Can J Anaesth 1991, 38:384-400,

35. Jellema WT, Groeneveld AB, van Goudoever J, Wesseling KH, Westerhof N, Lubbers MJ, Kesecioglu J, Van Lieshout JJ: Hemodynamic effects of intermittent manual lung hyperinflation in patients with septic shock. Heart Lung 2000, 29:356-366.

36. Paratz J, Lipman J, McAuliffe M: Effect of manual hyperinflation on hemodynamics, gas exchange, and respiratory mechanics in ventilated patients. J Intensive Care Med 2002, 17:317-324. 
37. Lu Q, Constantin JM, Nieszkowska A, Elman M, Vieira S, Rouby JJ:

Measurement of alveolar derecruitment in patients with acute lung

injury: computerized tomography versus pressure-volume curve. Crit Care 2006, 10:R95.

38. Heinze H, Schaaf B, Grefer J, Klotz K, Eichler W: The accuracy of the oxygen washout technique for functional residual capacity assessment during spontaneous breathing. Anesth Analg 2007, 104:598-604.

39. Rylander C, Hogman M, Perchiazzi G, Magnusson A, Hedenstierna G: Functional residual capacity and respiratory mechanics as indicators of aeration and collapse in experimental lung injury. Anesth Analg 2004, 98:782-789.

doi:10.1186/cc10340

Cite this article as: Paulus et al: Manual hyperinflation partly prevents

reductions of functional residual capacity in cardiac surgical patients - a randomized controlled trial. Critical Care 2011 15:R187.

\section{Submit your next manuscript to BioMed Central} and take full advantage of:

- Convenient online submission

- Thorough peer review

- No space constraints or color figure charges

- Immediate publication on acceptance

- Inclusion in PubMed, CAS, Scopus and Google Scholar

- Research which is freely available for redistribution

Submit your manuscript at www.biomedcentral.com/submit 